\title{
Les Introductions linguistiques aux éditions de textes, dir. F. DUVAL, C. GUILLOT-BARBANCE et F. ZINELLI
}

\section{Maurizio Busca}

\section{(2) OpenEdition}

\section{Journals}

\section{Edizione digitale}

URL: https://journals.openedition.org/studifrancesi/43619

DOI: 10.4000/studifrancesi.43619

ISSN: 2421-5856

\section{Editore}

Rosenberg \& Sellier

\section{Edizione cartacea}

Data di pubblicazione: 1 juin 2021

Paginazione: 201

ISSN: 0039-2944

Notizia bibliografica digitale

Maurizio Busca, «Les Introductions linguistiques aux éditions de textes, dir. F. duval, C. guillot-BaRbance et F. ZINELLI», Studi Francesi [Online], 193 (LXV | I) | 2021, online dal 01 juillet 2021, consultato il 15 octobre 2022. URL: http://journals.openedition.org/studifrancesi/43619; DOI: https://doi.org/10.4000/ studifrancesi.43619

Questo documento è stato generato automaticamente il 15 octobre 2022.

\section{(i) $\odot$

Creative Commons - Attribuzione - Non commerciale - Non opere derivate 4.0 Internazionale - CC BYNC-ND 4.0

https://creativecommons.org/licenses/by-nc-nd/4.0/ 
Les Introductions linguistiques aux éditions de textes, dir. F. DUVAL, C. GUILLOT-BARBANCE et F. ZINELLI

Maurizio Busca 


\section{NOTIZIA}

Les Introductions linguistiques aux éditions de textes, dir. F. DUVAL, C. GUILLOT-BARBANCE et F. ZINELLI, Paris, Classiques Garnier, 2019, «Histoire et évolution du français» 5, 377 pp.

Segnaliamo in questa sede una raccolta di saggi sul commento linguistico nelle edizioni di testi che, benché rivolta in primo luogo agli specialisti del Medioevo, saprà certamente fornire indicazioni metodologiche e strumenti critici utili anche agli studiosi del Cinquecento. L'iniziativa dei curatori muove dalla volontà di suscitare una riflessione articolata intorno a una componente spesso trascurata delle introduzioni alle edizioni critiche e semi-savantes, componente che l'evoluzione delle pratiche editoriali e soprattutto la diffusione degli strumenti informatici invitano tuttavia a riconsiderare. In un convegno tenutosi a Parigi (17-19 settembre 2015), due comunità scientifiche, quella dei filologi e quella dei linguisti, sono state invitate a confrontarsi sul tema del commento linguistico e, di conseguenza, sui rispettivi perimetri di azione e sulle modalità di interazione nell'ambito delle edizioni di testi. Gli articoli qui riuniti, che riprendono e prolungano le ricerche e le riflessioni avviate in quell'occasione, concedono largo spazio a questioni di carattere metodologico. Il denso intervento liminare dei curatori (pp. 7-32) introduce un dittico la cui prima parte («Introductions linguistiques et types d'éditions», pp. 33-131) accoglie cinque contributi sui formati e sulle pratiche di edizione e di introduzione, mentre la seconda parte («Les sections de l'introduction linguistique», pp. 133-323) consta di dieci saggi dedicati alle diverse componenti dell'introduzione linguistica: fonetica, morfologia, sintassi etc. Completano il volume gli indici e una corposa bibliografia (pp. 325-364). 